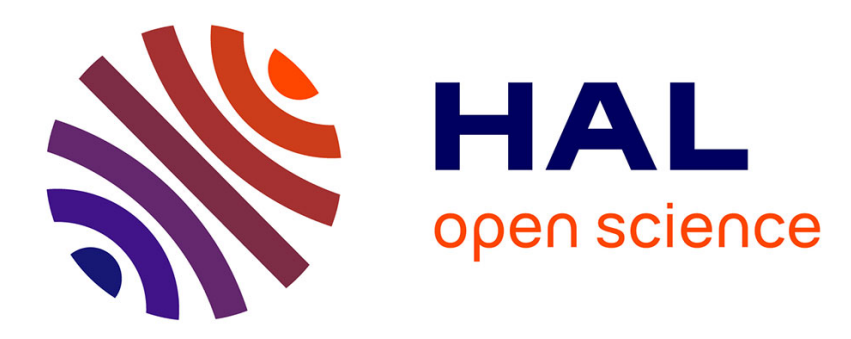

\title{
A possible explanation of the nature of dark matter by Newtonian mechanics
}

\author{
Nathalie Olivi-Tran, M Cannat
}

\section{To cite this version:}

Nathalie Olivi-Tran, M Cannat. A possible explanation of the nature of dark matter by Newtonian mechanics. 2015. hal-01230773

\section{HAL Id: hal-01230773 https://hal.science/hal-01230773}

Preprint submitted on 19 Nov 2015

HAL is a multi-disciplinary open access archive for the deposit and dissemination of scientific research documents, whether they are published or not. The documents may come from teaching and research institutions in France or abroad, or from public or private research centers.
L'archive ouverte pluridisciplinaire HAL, est destinée au dépôt et à la diffusion de documents scientifiques de niveau recherche, publiés ou non, émanant des établissements d'enseignement et de recherche français ou étrangers, des laboratoires publics ou privés. 


\title{
A possible explanation of the nature of dark matter by Newtonian mechanics
}

\author{
N. Olivi-Tran and M.Cannat \\ ${ }^{1}$ Laboratoire Charles Coulomb, Universite de Montpellier, \\ CNRS, UMR 5221, place Eugene Bataillon, \\ 34095 Montpellier cedex 5, France, \\ email: Nathalie.Olivi-Tran@umontpellier.fr
}

(Dated: November 18, 2015)

\begin{abstract}
We calculate the trajectory of a moving object on earth and the trajectory of the earth around the sun in a fourdimensional space $(x, y, z, t)$. We see that the trajectory has a mass: this is what is called dark matter which mass depends on the mass of the moving object. Indeed the deformation of space, the track, deviates light as we are at the hypersurface of the universe, and that is the method of measurement of the 'mass' of the universe.
\end{abstract}

Keywords: dark matter; Newtonian mechanics 


\section{INTRODUCTION}

I make here the hypothesis that our three dimensional universe with physical laws is embedded in a four-dimensional space where no physical law exist $[1,2]$. Time is a function of the radius of curvature of our universe and this leads to the acceleration of the expansion of our universe [4].

The model of dark matter that I present here is based on the fluctuations of the hypersurface of our universe. Our universe is three dimensional and curved, therefore it may be embedded in a four dimensional space with no curvature. The hyper-surface of our universe is superimposed to our present universe. But this hyper-surface is not 'smooth', this means that it may contain fluctuations. These fluctuations are due to real matter (due to the changes of curvature due to gravitation) but also to dark matter (or at least 'are' dark matter). Indeed, the local changes in the curvature of our universe may lead to what we call dark matter. This dark matter, although it is only a local deformation of the hyper-surface of our universe, may deviate radiations and can account for gravitational effects [5].

\section{TRAJECTORIES}

In Newtonian mechanics

$$
m \mathbf{a}=m \mathbf{g}
$$

where $\mathbf{a}$ is the acceleration, $\mathrm{m}$ the mass of the moving object and $\mathbf{g}$ the gravitational acceleration on a given point on earth. As said before, our universe is threedimensional and curved and it can be embedded in a fourdimensional euclidean space. So we integrate equation (1) over $x, y, z$ and $t$ even if this corresponds not exactly to a euclidean space because $\mathrm{t}$ is not linearly proportional to a space dimension [1-4].

$$
\begin{array}{r}
\int_{\infty}^{\infty} m \mathbf{a} d x d y d z d t= \\
\int_{\infty}^{\infty} m \mathbf{g} d x d y d z d t
\end{array}
$$

and

$$
\begin{array}{r}
\int_{\infty}^{\infty} m \mathbf{v} d x d y d z d t= \\
\int_{\infty}^{\infty} m \mathbf{g}(x \mathbf{i}+y \mathbf{j}+z \mathbf{k}+t)+ \\
m \mathbf{v}_{\mathbf{0}}+\left(x_{0} \mathbf{i}+y_{0} \mathbf{j}+z_{0} \mathbf{k}+t_{0}\right) d x d y d z d t
\end{array}
$$


and

$$
\begin{array}{r}
m(x \mathbf{i}+y \mathbf{j}+z \mathbf{k})= \\
m \mathbf{g}\left(x^{2} / 2 \mathbf{i}+y^{2} / 2 \mathbf{j}+z^{2} / 2 \mathbf{k}+t^{2} / 2\right)+ \\
m \mathbf{v}_{0}(x \mathbf{i}+y \mathbf{j}+z \mathbf{k}+t)+\left(x_{0} x \mathbf{i}+\right. \\
\left.y_{0} y \mathbf{j}+z_{0} z \mathbf{k}+t_{0} t\right)
\end{array}
$$

where $\mathbf{v}_{\mathbf{0}}$ is the initial velocity and $x_{0}, y_{0}, z_{0}, t_{0}$ its starting point. So the trajectory of the object is a second order equation and not exactly a parabola.

For the trajectory of earth around the sun we have, in Newtonian mechanics:

$$
m \mathbf{a}=\frac{G M m}{r^{2}}\left(x_{r} \mathbf{i}+y_{r} \mathbf{j}+z_{r} \mathbf{k}\right)
$$

where $G$ is the gravitational constant in Newtonian mechanics, $r$ is the distance between the sun and earth at time $t_{0}, x_{r} \mathbf{i}+y_{r} \mathbf{j}+z_{r} \mathbf{k}$ the vector directed from earth to the sun at time $t_{0} \cdot$

$$
\begin{array}{r}
\int_{\infty}^{\infty} m \mathbf{a} d x d y d z d t= \\
\int_{\infty}^{\infty} \frac{G M m}{r^{2}}\left(x_{r} \mathbf{i}+y_{r} \mathbf{j}+z_{r} \mathbf{k}\right) d x d y d z d t
\end{array}
$$

and

$$
\begin{array}{r}
\int_{\infty}^{\infty} m \mathbf{v} d x d y d z d t= \\
\int_{\infty}^{\infty}\left(\frac{G M m}{r^{2}}\left(x_{r} \mathbf{i}+y_{r} \mathbf{j}+z_{r} \mathbf{k}\right)(x \mathbf{i}+y \mathbf{j}+z \mathbf{k}+t)+\right. \\
\left.m \mathbf{v}_{\mathbf{0}}+\left(x_{0} \mathbf{i}+y_{0} \mathbf{j}+z_{0} \mathbf{k}+t_{0}\right)\right) d x d y d z d t
\end{array}
$$

and

$$
\begin{array}{r}
m(x \mathbf{i}+y \mathbf{j}+z \mathbf{k})= \\
\frac{G M m}{r^{2}}\left(x_{r} \mathbf{i}+y_{r} \mathbf{j}+z_{r} \mathbf{k}\right)\left(x^{2} / 2 \mathbf{i}+y^{2} / 2 \mathbf{j}+z^{2} / 2 \mathbf{k}+t^{2} / 2\right)+ \\
m \mathbf{v}_{0}(x \mathbf{i}+y \mathbf{j}+z \mathbf{k}+t)+\left(x_{0} x \mathbf{i}+y_{0} y \mathbf{j}+z_{0} z \mathbf{k}+t_{0} t\right)
\end{array}
$$

This is the trajectory of earth around the sun.You may see that the trajectory has a mass $\mathrm{m}$ : this is dark matter; this is mass without the presence of an object or more precisely deformation of space due to the former presence of an object. 


\section{CONCLUSION}

Dark matter is in fact the track of the planets in the solar system, and of objects in the universe. This explains why we do not 'see' all the mass present in the universe. Indeed the present methods use the trajectory of electromagnetic waves and particles coming from space to measure the mass of the universe and these are deviated by the track of real mass.

Acknowledgments: We acknowledge interesting discussions with H.C. and N.G.

[1] N.Olivi-Tran and P.M.Gauthier, The FLRW cosmological model revisited: Relation on the local time with the local curvature and consequences on the Heisenberg uncertainty principle Adv. Studies Theor. Phys. vol.2 no 6 (2008) 267-270

[2] N.Olivi-Tran What if our three dimensional curved universe was embedded in four dimensional space? Consequences on the EPR paradox Adv. Studies Theor. Phys., Vol. 3, (2009), no. 12, $489-492$

[3] N.Olivi-Tran Dimensional analysis of Einstein's fields equations Adv. Studies Theor. Phys., Vol. 3, (2009), no. 1, 9 - 12

[4] N.Olivi-Tran Is the rate of expansion of our universe really accelerating? Adv. Studies Theor. Phys.Vol. 5, 2011, no. 13, 633 - 638

[5] Trimble, Virginia (1987). "Existence and nature of dark matter in the universe". "Annual Review of Astronomy and Astrophysics" 25: 425472. 